\title{
The Endocannabinoid System and Oligodendrocytes in Health and Disease
}

\author{
Alexander A. Ilyasov ${ }^{1,2}$, Carolanne E. Milligan ${ }^{1,3}$, Emily P. Pharr ${ }^{1,4}$ and Allyn C. Howlett ${ }^{1,2 *}$ \\ ${ }^{1}$ Graduate Program in Neuroscience, Wake Forest School of Medicine, Winston Salem, NC, United States, ${ }^{2}$ Department \\ of Physiology and Pharmacology and Center for Research on Substance Use and Addiction, Wake Forest School \\ of Medicine, Winston-Salem, NC, United States, ${ }^{3}$ Department of Neurobiology and Anatomy, Wake Forest School \\ of Medicine, Winston-Salem, NC, United States, ${ }^{4}$ Department of Neurology and Comprehensive Multiple Sclerosis Center, \\ Wake Forest School of Medicine, Winston-Salem, NC, United States
}

\section{OPEN ACCESS}

Edited by:

Fabricio A. Pamplona,

Entourage Phytolab, Brazil

Reviewed by:

Thomas Heinbockel, Howard University, United States Styliani Vlachou,

Dublin City University, Ireland

*Correspondence:

Allyn C. Howlett

ahowlett@wakehealth.edu

Specialty section:

This article was submitted to

Neuropharmacology,

a section of the journal

Frontiers in Neuroscience

Received: 26 April 2018 Accepted: 24 September 2018 Published: 26 October 2018

Citation:

Ilyasov AA, Milligan CE, Pharr EP and Howlett AC (2018) The Endocannabinoid System and Oligodendrocytes in Health and Disease. Front. Neurosci. 12:733. doi: 10.3389/fnins.2018.00733
Cannabinoid-based interventions are being explored for central nervous system (CNS) pathologies such as neurodegeneration, demyelination, epilepsy, stroke, and trauma. As these disease states involve dysregulation of myelin integrity and/or remyelination, it is important to consider effects of the endocannabinoid system on oligodendrocytes and their precursors. In this review, we examine research reports on the effects of the endocannabinoid system (ECS) components on oligodendrocytes and their precursors, with a focus on therapeutic implications. Cannabinoid ligands and modulators of the endocannabinoid system promote cell signaling in oligodendrocyte precursor survival, proliferation, migration and differentiation, and mature oligodendrocyte survival and myelination. Agonist stimulation of oligodendrocyte precursor cells (OPCs) at both $\mathrm{CB}_{1}$ and $\mathrm{CB}_{2}$ receptors counter apoptotic processes via Akt/PI3K, and promote proliferation via Akt/mTOR and ERK pathways. $\mathrm{CB}_{1}$ receptors in radial glia promote proliferation and conversion to progenitors fated to become oligodendroglia, whereas $\mathrm{CB}_{2}$ receptors promote OPC migration in neonatal development. OPCs produce 2-arachidonoylglycerol (2-AG), stimulating cannabinoid receptor-mediated ERK pathways responsible for differentiation to arborized, myelin basic protein (MBP)producing oligodendrocytes. In cell culture models of excitotoxicity, increased reactive oxygen species, and depolarization-dependent calcium influx, $\mathrm{CB}_{1}$ agonists improved viability of oligodendrocytes. In transient and permanent middle cerebral artery occlusion models of anoxic stroke, WIN55212-2 increased OPC proliferation and maturation to oligodendroglia, thereby reducing cerebral tissue damage. In several models of rodent encephalomyelitis, chronic treatment with cannabinoid agonists ameliorated the damage by promoting OPC survival and oligodendrocyte function. Pharmacotherapeutic strategies based upon ECS and oligodendrocyte production and survival should be considered.

Keywords: 2-arachidonoylglycerol (2-AG), CP55940, HU210, multiple sclerosis (MS), neural stem cells (NSCs), oligodendrocyte precursor cells (OPCs), SR141716, WIN55212-2 


\section{INTRODUCTION}

Phytocannabinoid use in management of multiple sclerosis (MS) symptoms (Consroe et al., 1997) has led to clinical trial evidence for the efficacy of tetrahydrocannabinol (THC)/cannabidiol (CBD) oromucosal spray (Sativex) in controlling spasticity and pain (Wade et al., 2010; Giacoppo et al., 2017). MS, a demyelinating disease characterized by persistent neuroinflammation and progressive central nervous system (CNS) demyelination (Kutzelnigg and Lassmann, 2014), is only one of many demyelinating neurodegenerative diseases involving oligodendrocytes, the myelinating cells of the CNS. The endocannabinoid system (ECS) (Howlett et al., 2002; Pertwee et al., 2010) involvement in neuroprotection (Panikashvili et al., 2001; van der Stelt and Di Marzo, 2005; Martinez-Orgado et al., 2007; Sanchez and García-Merino, 2012) and the immune system in CNS diseases (Croxford and Yamamura, 2005; Rom and Persidsky, 2013; Chiurchiu et al., 2015; Olah et al., 2017) have been reviewed. Here, we address ECS effects on oligodendrocytes and their precursors, in order to evaluate the evolving research around cannabinoids in healthy development and in demyelinating neurodegenerative diseases.

\section{CANNABINOIDS, OLIGODENDROCYTE PRECURSOR CELLS AND OLIGODENDROCYTES IN HEALTH}

Oligodendrocytes, myelinating cells of the vertebrate CNS, enable neurons to signal more energy-efficiently and at higher speed due to saltatory conduction, and maintain axonal integrity through trophic and metabolic support (Michalski and Kothary, 2015; Simons and Nave, 2015). Generation of oligodendrocytes is an ongoing process, starting in embryonic development and continuing throughout life (Baumann and Pham-Dinh, 2001; Trotter et al., 2010; Dimou and Gallo, 2015; Michalski and Kothary, 2015). In brief, oligodendrocyte precursor cells (OPCs), also known as NG2-glia, O-2A progenitors, polydendrocytes, or synantocytes, arise from neural stem cells (NSCs), and preferentially populate distinct areas of the developing CNS in lineage- and time-specific waves (Richardson et al., 2006). Upon arrival, many undergo apoptosis, while many others either mature into myelinating oligodendrocytes or persist as progenitors and remain capable of self-renewal as well as production of mature oligodendrocytes well into adulthood (Dawson et al., 2003). These progenitors become distributed throughout gray and white matter and maintain their respective domains by continuously sampling their environment, able to expand to neighboring areas vacated by other OPCs (Kirby et al., 2006; Hughes et al., 2013).

Despite this interchangeability, it is becoming increasingly clear that oligodendrocyte precursors represent a heterogeneous group, distinct in their origin, signaling, and ability to revert differentiation to produce neurons and astrocytes (Trotter et al., 2010; Dimou and Gallo, 2015; Nishiyama et al., 2016; Vigano and Dimou, 2016). Regardless of the differences, all OPCs rely on the processes of proliferation, migration, and differentiation to become mature, functioning oligodendrocytes (Baumann and Pham-Dinh, 2001; Miron et al., 2011; Dubois et al., 2014; Sampaio-Baptista and Johansen-Berg, 2017). As these steps are differentially regulated (Marinelli et al., 2016), it is important to look at the effects of cannabinoid agonists on each (see Figure 1).

\section{Survival}

Reports of cannabinoid receptors in newborn rat white matter by immunostaining (Berrendero et al., 1999), led to subsequent studies exploring cells in vitro. OPCs were isolated from newborn Wistar rat forebrains and expanded by incubation in serumfree defined media with supplements including platelet-derived growth factor (PDGF) and fibroblast growth factor (FGF) (Molina-Holgado et al., 2002). OPCs could be differentiated into myelin basic protein (MBP)-producing mature oligodendrocytes by incubation in serum-free defined media in which PDGF and FGF were replaced by triiodothyronine (T3). As ascertained by RT-PCR, Western blot, and immunohistochemistry, both $\mathrm{OPC}$ and mature oligodendrocytes expressed both $\mathrm{CB}_{1}$ and $\mathrm{CB}_{2}$ cannabinoid receptors (Molina-Holgado et al., 2002). Because activation of cannabinoid receptors confers neuroprotection (van der Stelt and Di Marzo, 2005; Martinez-Orgado et al., 2007; Sanchez and García-Merino, 2012), the influence of cannabinoid agonists on viability of OPCs was investigated. Upon incubation in serum-free DMEM/F12 media for $12 \mathrm{~h}$, nearly half of OPCs underwent apoptosis (Molina-Holgado et al., 2002). However, most were rescued by concurrent supplementation with $\mathrm{CB}_{1}$ agonist arachidonyl-2'-chloroethylamide (ACEA, $25 \mathrm{nM}$ ) or $\mathrm{CB}_{1} / \mathrm{CB}_{2}$ agonists WIN55212-2 (25 nM) or HU210 (500 nM). Co-treatment with $\mathrm{CB}_{1}$ antagonist SR141716 $(1 \mu \mathrm{M})$ abolished the anti-apoptotic effect of ACEA, but not of WIN55212-2 or HU210. Both SR141716 plus $\mathrm{CB}_{2}$ antagonist SR144528 (1 $\left.\mu \mathrm{M}\right)$ were required to nullify the pro-survival effect of HU210. These results show that the activation of either $\mathrm{CB}_{1}$ or $\mathrm{CB}_{2}$ receptors

OPC Lifecycle
CB1R
Differentiation
FIGURE 1 | Evidence for $\mathrm{CB}_{1}$ or $\mathrm{CB}_{2}$ receptor activation or endogenous
2-Arachidonoylglycerol modulation of Oligodendrocyte Precursor Cell Life
Cycle. +, Promote; $\mathrm{O}$, No effect; ? Unknown. See the text for details and
original references.


could be sufficient in promoting OPC survival under conditions of trophic factor deprivation. The mechanism includes activation of the phosphatidylinositol 3-kinase (PI3K)/Akt pathway, a known modulator of OPC survival (Vemuri and McMorris, 1996; Ebner et al., 2000). Applying each of the three agonists correlated with increased Akt phosphorylation, while co-treatment with PI3K inhibitors LY294002 $(10 \mu \mathrm{M})$ or wortmannin $(100 \mathrm{nM})$ nullified the effects of WIN55212-2 and HU210 on both Akt phosphorylation and cell survival (Molina-Holgado et al., 2002). Thus, stimulation of Akt/PI3K pathways via $\mathrm{CB}_{1}$ and $\mathrm{CB}_{2}$ receptors present in OPCs can curtail apoptotic processes and promote survival.

\section{Proliferation}

Molina-Holgado and colleagues explored the ability of the endocannabinoid system to modulate OPC proliferation and self-renewal (Gomez et al., 2015). In cultured OPCs (MolinaHolgado et al., 2002), 24-h blockade of $\mathrm{CB}_{1}$ receptors with AM281 $(1 \mu \mathrm{M}), \mathrm{CB}_{2}$ receptors with AM630 $(1 \mu \mathrm{M})$, or synthesis of 2-arachidonoylglycerol (2-AG) by diacylglycerol lipase $\alpha$ and $\beta$ (DAGLs) with RHC80267 $(5 \mu \mathrm{M})$, led to reduction in PDGF/FGF-stimulated OPC proliferation. In the absence of PDGF and FGF, OPC proliferation increased in response to 24-h application of $\mathrm{CB}_{1}$ agonist ACEA $(0.5 \mu \mathrm{M}), \mathrm{CB}_{2}$ agonist JWH133 $(0.5 \mu \mathrm{M}), 2-\mathrm{AG}(1 \mu \mathrm{M})$, or JZL184 $(1 \mu \mathrm{M})$ which blocks the 2-AG metabolizing enzyme monoacylglycerol lipase (MAGL). The effect depended on phosphorylation of Akt and mammalian target of rapamycin (mTOR), as their blockers LY294002 $(5 \mu \mathrm{M})$ and rapamycin $(3 \mathrm{nM})$, respectively $(24 \mathrm{~h})$, decreased the proliferative effects of ACEA, JWH133, and JZL184. Extracellular signal regulated-kinase (ERK) 1/2 phosphorylation was decreased in cells treated with the 2AG synthesis inhibitor RHC80267, as well as with $\mathrm{CB}_{1}$ and $\mathrm{CB}_{2}$ antagonists AM281 and AM630, respectively. These results extend the impact of cannabinoid receptor activation from promoting OPC survival (Molina-Holgado et al., 2002) to increasing proliferation, while also implicating cannabinoidmediated Akt/mTOR and ERK pathways, known to play a role throughout OPC development to myelination (Gonsalvez et al., 2016; Figlia et al., 2018).

\section{Migration}

NSCs of postnatal subventricular zone (SVZ) emigrate the neurogenic niche in the form of neuroblasts or OPCs (Marshall et al., 2003). In rat CNS, both myelination and SVZ gliogenesis peak at postnatal day (PD) 15 (Bjelke and Seiger, 1989; Hamano et al., 1996), making this an optimal time-point for exploring cannabinoid effects on OPC proliferation and migration from postnatal SVZ. Immunohistochemical analysis of PD7 and PD15 Wistar rat brain revealed that the $\mathrm{CB}_{1}$ receptor was primarily expressed by radial glia (Aré-Martín et al., 2007), which can transform to NSCs (Merkle et al., 2004). However, the $\mathrm{CB}_{2}$ receptor co-stained with poly-sialylated neural cell adhesion molecule (PSA-NCAM) (Aré-Martín et al., 2007), a marker of migration in OPCs and neuroblasts (Doetsch et al., 1999; Menn et al., 2006). The $\mathrm{CB}_{1}$ agonist ACEA (escalating dose $1.25-2.5 \mathrm{mg} / \mathrm{kg}$, SC daily PD1 to PD14) increased PD15
SVZ staining for $4 \mathrm{~A} 4$, a marker of radial glia proliferation (Howard et al., 2006), and Olig2 (Aré-Martín et al., 2007), which is expressed in glial precursors fated to become oligodendrocytes (Mitew et al., 2014). Similar treatment with $\mathrm{CB}_{2}$ agonist JWH056 (escalating dose $2.5-5.0 \mathrm{mg} / \mathrm{kg}$, SC) increased SVZ staining for PSA-NCAM. Activation of both $\mathrm{CB}_{1}$ and $\mathrm{CB}_{2}$ receptors by WIN55212-2 (escalating dose $2.5-5.0 \mathrm{mg} / \mathrm{kg}, \mathrm{SC}$ ) increased MBP staining in the external capsule, which was inhibited below control values by concurrent administration of either SR141716 $\left(\mathrm{CB}_{1}\right)$ or SR144528 $\left(\mathrm{CB}_{2}\right)$ antagonists (escalating dose 2-4 mg/kg, SC) (Aré-Martín et al., 2007). These results support the involvement of $\mathrm{CB}_{1}$ receptors in radial glia proliferation and conversion to oligodendrocytes, but $\mathrm{CB}_{2}$ receptors in $\mathrm{OPC}$ migration, leading to functional oligodendrocytes in neonatal myelination.

Studies have examined cannabinoid agonist impact on rodent SVZ proliferation beyond the newborn stage. In juvenile (PD35PD48) Lewis rats, WIN55212-2 (2 mg/kg, IP bid, 2-weeks) increased SVZ BrdU staining, without changing the ratio of progenitors committed to neuronal or OPC fates, or the number of cells undergoing caspase- 3 mediated apoptosis (Bortolato et al., 2014). These results are consistent with findings that genetic ablation of $\mathrm{CB}_{1}$ receptors decreased progenitor proliferation in adult mouse SVZ (Jin et al., 2004; Kim et al., 2006). In adult mice, cannabidiol (CBD; $3 \mathrm{mg} / \mathrm{kg}$ IP daily for 14 days) increased SVZ proliferative markers Ki67 and BrdU staining (Schiavon et al., 2016). However, CBD at $30 \mathrm{mg} / \mathrm{kg}$ decreased proliferation markers (Schiavon et al., 2016), highlighting the importance of dose.

\section{Differentiation to Mature Oligodendrocytes}

Molina-Holgado et al. (2002) investigated OPC differentiation using isolated OPCs differentiated with T3 $(30 \mathrm{ng} / \mathrm{mL}, 48 \mathrm{~h}$ ) in the absence of PDGF/FGF (Gomez et al., 2011). Activating either cannabinoid receptor (ACEA for $\mathrm{CB}_{1}$ and JWH133 for $\left.\mathrm{CB}_{2}, 0.5 \mu \mathrm{M}\right)$ increased OPC branching and accumulation of MBP (Western blot). The $\mathrm{CB}_{1} / \mathrm{CB}_{2}$ agonist HU210 $(0.5 \mu \mathrm{M})$ evoked the same responses, which could be abolished by either AM281 $\left(\mathrm{CB}_{1}\right)$ or AM630 $\left(\mathrm{CB}_{2} ; 1 \mu \mathrm{M}\right)$. The mechanism for HU210-mediated OPC arborization and production of MBP involved PI3K/Akt and mTOR pathways, as these effects were blocked with LY290042 $(2.5 \mu \mathrm{M})$ and rapamycin $(0.75 \mathrm{nM})$, respectively. Gomez et al. (2010) found the Western blot level of DAGLs to be higher in OPCs, whereas the level of MAGL was higher in mature oligodendrocytes, culminating in the finding that OPCs accumulated a greater content of 2-AG than mature oligodendrocytes. Levels of anandamide (AEA) were low and did not differ between the cell stages (Gomez et al., 2010). Differentiation, denoted by branching morphology and levels of MBP after $96 \mathrm{~h}$, was increased by MAGL inhibitor JZL184 $(1 \mu \mathrm{M})$, and decreased by DAGL inhibitor RHC80267 $(5 \mu \mathrm{M})$, with exogenous 2-AG $(2 \mu \mathrm{M})$ abolishing the effect of blocking its synthesis. Inhibition of the ERK pathway by the MEK blocker PD98059 $(10 \mu \mathrm{M})$ abolished Western blot staining for MBP, implicating the ERK pathway in differentiation. In a $\mathrm{CB}_{1}$ 
receptor mRNA-expressing human oligodendrocyte precursor line HOG16, WIN55212-2 (1 $\mu \mathrm{M}, 24 \mathrm{~h})$ increased MBP mRNA expression, particularly in cells treated with T3-supplemented differentiating medium (Tomas-Roig et al., 2016). Collectively, these studies suggest that endogenous 2-AG in OPCs triggers the ERK pathway, leading to the maturation of arborized, MBPproducing oligodendrocytes.

\section{THE ECS AND OPCS-OLIGODENDROCYTES IN MODELS OF DISEASE}

The role of cannabinoids in OPCs and oligodendrocytes under stress has been evaluated in models of insults such as excitotoxicity (Shouman et al., 2006; Bernal-Chico et al., 2015), reactive oxygen species (ROS) toxicity (Ribeiro et al., 2013), KClinduced depolarization (Mato et al., 2009), as well as in models of stroke (Fernández-López et al., 2010; Sun et al., 2013a,b), spinal cord injury (SCI) (Marsicano et al., 2003; Arevalo-Martin et al., 2010), and demyelination (Solbrig et al., 2010; Ribeiro et al., 2013; Bernal-Chico et al., 2015; Wen et al., 2015; Feliu et al., 2017).

\section{Cannabinoids and OPC-Oligodendrocytes in Cytopathology Models}

The ability of cannabinoid agonists to protect neurons from excitotoxicity is well known (Shen and Thayer, 1998; Hansen et al., 2002; Marsicano et al., 2003; van der Stelt and Di Marzo, 2005). Likewise, ECS involvement in OPC and oligodendrocyte excitotoxicity has recently been explored (Shouman et al., 2006; Bernal-Chico et al., 2015). Newborn (PD5) Sprague Dawley rats received AMPA/kainate agonist bromowillardine (15 $\mu \mathrm{g}$, IC), immediately followed by AEA (10 mg/kg, IP) (Shouman et al., 2006). AEA significantly increased OPC density within the periventricular white matter lesion after 1 day, and increased MBP staining after 5 days. The ECS in excitotoxicity was also investigated in mature oligodendrocytes (Bernal-Chico et al., 2015). OPCs were isolated from the cerebral cortex of newborn wildtype or $\mathrm{CB}_{1}-\mathrm{KO}$ Sprague-Dawley rats and differentiated with T3 minus growth factors. Oligodendrocytes were exposed to AMPA plus cyclothiazide $(10 \mu \mathrm{M}: 100 \mu \mathrm{M})$ for $15 \mathrm{~min}$, resulting in excessive cytosolic calcium, reactive oxygen species (ROS) production, and cell death (Bernal-Chico et al., 2015). A 30-min pretreatment with $\mathrm{CB}_{1}$ agonist ACEA (25 nM), endocannabinoids AEA or 2-AG $(1 \mu \mathrm{M})$, or MAGL inhibitor JZL184 (25 nM) reduced cell death (Bernal-Chico et al., 2015). No protection occurred in oligodendrocytes lacking $\mathrm{CB}_{1}$ receptors, or pretreated with $\mathrm{CB}_{2}$ agonist JWH133 (25 nM) or the inhibitor of AEA metabolizing enzyme fatty acid amide hydrolase (FAAH) URB597 (10 nM - $1 \mu \mathrm{M})$. These findings implicate endocannabinoids and $\mathrm{CB}_{1}$ receptors in improved viability of oligodendrocytes in excitotoxic conditions.

Due to their high metabolic demand, oligodendrocytes are vulnerable to elevated levels of ROS (McTigue and Tripathi, 2008; Roth and Nunez, 2016), although less so than their precursors (Back et al., 1998). To investigate how cannabinoid agonists affect oligodendrocyte survival, precursors isolated from PD2-PD3 Sprague-Dawley rat brains were differentiated by T3 plus ciliary neurotrophic factor for 2 weeks, and exposed to a peroxynitrite generator SIN-1 (1 mM) (Zhang et al., 2006, 2007) for $2 \mathrm{~h}$ (Ribeiro et al., 2013). Concurrent treatment with $\mathrm{CB}_{1} / \mathrm{CB}_{2}$ agonists CP55940 (1-3 $\left.\mu \mathrm{M}\right)$, WIN55212-2 $(10 \mu \mathrm{M})$, or anandamide/THC hybrid CB52 $(3-10 \mu \mathrm{M})$, reduced cell death. CB52's mechanism included activation of $\mathrm{CB}_{2}$ receptors, as $\mathrm{CB}_{2}$ antagonist $\mathrm{AM} 630(10 \mu \mathrm{M})$, but not $\mathrm{CB}_{1}$ antagonist $\mathrm{AM} 281$ $(10 \mu \mathrm{M})$ reduced its effectiveness, while $\mathrm{CB}_{2}$ agonists AM1241 and JWH015 partially replicated it (Ribeiro et al., 2013).

The ability of $\mathrm{CB}_{1}$ agonists to inhibit depolarizationdependent calcium channels, as observed in neurons (Howlett et al., 2002), was explored in oligodendrocytes (Mato et al., 2009). Precursors were isolated from optic nerve of PD12 SpragueDawley rats, differentiated by 2 -day incubation in defined media, and exposed to $\mathrm{KCl}$ (50 $\mathrm{mM}, 1 \mathrm{~min})$ to induce depolarization (Mato et al., 2009). Resulting calcium influx was decreased by $\mathrm{CB}_{1}$ agonist $\mathrm{ACEA}(1 \mu \mathrm{M})$ or $\mathrm{CB}_{1} / \mathrm{CB}_{2}$ agonists THC $(3 \mu \mathrm{M})$, CP55940 $(3 \mu \mathrm{M})$, AEA $(3 \mu \mathrm{M})$ or $2-\mathrm{AG}(3 \mu \mathrm{M})$, but not $\mathrm{CB}_{2}$ agonist JWH133 $(3 \mu \mathrm{M})$. Oligodendrocytes from $\mathrm{CB}_{1}$ $\mathrm{KO}$ mice were less responsive to AEA and ACEA, although not completely unresponsive, suggesting other targets exist such as transient receptor potential vanilloid receptor-1 (TRPV1) (Ross, 2003; Ruparel et al., 2011), expressed in oligodendrocytes (Gonzalez-Reyes et al., 2013). In contrast, CBD (100 nM, 20$30 \mathrm{~min}$ ) reduced oligodendrocyte viability, in part through an increase in intracellular calcium (Mato et al., 2010). CBD (1 $\mu \mathrm{M}$, $10 \mathrm{~min}$ ) increased oligodendrocyte production of ROS, and induced apoptosis through mitochondria-mediated activation of caspase- 8 and -9 and their downstream effector caspase-3, as well as poly-(ADP ribose) polymerase-1 (PARP-1), triggered by caspase-independent mitochondrial apoptosis-induced factor (AIF) (Hong et al., 2004).

\section{ECS and Oligodendrocytes in Stroke and Traumatic Injury}

Oligodendrocytes are vulnerable to ischemic conditions and their replacement via OPCs has been found to aid recovery (Dewar et al., 2003; Zhang et al., 2013, 2016). The impact of the ECS was studied in adult (Sun et al., 2013a,b) and neonatal (Fernández-López et al., 2010) rat models of middle cerebral artery occlusion (MCAO). In transient (2 h) MCAO (Sun et al., 2013a), WIN55212-2 (9 mg/kg, IP immediately after reperfusion and daily) increased staining for penumbral OPCs and mature oligodendrocytes at 4, 7, and 14 days post ischemia (DPI), and penumbral myelin density at 14 DPI. WIN552122 reduced penumbral expression of caspase-3 in OPCs at 7 DPI, which correlated with reduced ERK1/2 phosphorylation. These effects were ameliorated by $\mathrm{CB}_{1}$ antagonist SR141716 $(1 \mathrm{mg} / \mathrm{kg}, \mathrm{IV})$. In adult male Sprague-Dawley rats, WIN55212$2(9 \mathrm{mg} / \mathrm{kg}, \mathrm{IV})$ was given within $2 \mathrm{~h}$ after permanent MCAO, with anoxia damage quantitated after 24 h (Sun et al., 2013b). WIN55212-2 treatment increased OPC proliferation within the penumbra and ipsilateral SVZ, and decreased penumbral OPC expression of tau-1, an oligodendrocyte marker of ischemic 
stress (Dewar and Dawson, 1995; Irving et al., 1996). Both effects were partially due to $\mathrm{CB}_{1}$ receptor activation (Sun et al., 2013b). In a permanent MCAO model in neonatal PD7 Wistar rats (Fernández-López et al., 2010), WIN552122 (1 $\mathrm{mg} / \mathrm{kg}$, IP daily for 7 days) increased ipsilateral SVZ OPC proliferation and number of penumbral OPCs at 7 DPI. WIN55212-2 increased the number of mature penumbral oligodendrocytes at 14 and 28 DPI, and accelerated complete MBP recovery. Consistent with earlier findings (Goncalves et al., 2008; Bortolato et al., 2014), WIN55212-2 increased SVZ OPC proliferation even in the absence of ischemia. Although preclinical results appear promising for cannabinoid pharmacotherapies for anoxic demyelination, SVZ neurogenic response to stroke varies greatly between rodents and humans (Kahle and Bix, 2013).

The endocannabinoid 2-AG has been shown to be neuroprotective after traumatic brain injury (Panikashvili et al., 2001), and 2-AG is elevated after spinal trauma (Marsicano et al., 2003; Garcia-Ovejero et al., 2009). Thus, the impact of 2-AG on oligodendrocyte survival was explored in a model of contusive SCI generated by a dropped weight in male adult Wistar rats (Arevalo-Martin et al., 2010). 2-AG (5 mg/kg, IP 30 min after injury) preserved myelin integrity and reduced oligodendrocyte death at the epicenter ( 1 day post-injury), with the same effects seen as far as $10 \mathrm{~mm}$ rostral of epicenter ( 1 and 7 days post-injury). Co-administration of both $\mathrm{CB}_{1}$ and $\mathrm{CB}_{2}$ antagonists (AM281 and AM630, respectively; $3 \mathrm{mg} / \mathrm{kg}$, IP), but not by either alone, could reverse the effects of 2-AG. These results support the idea that improved oligodendrocyte survival and preserved white matter integrity underlie the cannabinoidmediated improvement in SCI recovery (Arevalo-Martin et al., 2012).

\section{ECS and Models of Demyelination}

To investigate demyelination in a mouse model of experimental autoimmune encephalomyelitis (EAE), PD49 or PD56 C57BL/6 mice received a single injection of myelin oligodendrocyte glycoprotein peptide (MOG 35-55), followed by injections of pertussis toxin on the day of MOG inoculation and again 2 days afterward (Bernal-Chico et al., 2015). MAGL inhibitor JZL184 ( $8 \mathrm{mg} / \mathrm{kg}$, IP daily for 3 weeks, starting on day 14 postinoculation) ameliorated the reduction in spinal cord white matter staining (Bernal-Chico et al., 2015). Similar results in the EAE model were achieved by THC (Moreno-Martet et al., 2015), CBD (Giacoppo et al., 2015), cannabigerol quinone (Carrillo-Salinas et al., 2014), and $\mathrm{CB}_{2}$ agonist HU308 (Shao et al., 2014). The effects of CB52 on demyelination EAE (Ribeiro et al., 2013) showed that when initiated before symptom development (3 days) or after clinical disease onset (12 or 20 days), CB52 (2 mg/kg, IP daily) ameliorated the loss of staining for spinal cord myelin and mature oligodendrocytes at day-30. In contrast to CB52's action on cultured oligodendrocytes in vitro (Ribeiro et al., 2013), both of its effects in vivo were blocked by $\mathrm{CB}_{1}$ antagonist $\mathrm{AM} 281(2 \mathrm{mg} / \mathrm{kg})$, but not by $\mathrm{CB}_{2}$ antagonist AM630 $(2 \mathrm{mg} / \mathrm{kg})$.

Microglia are an integral part of demyelinating diseases' neuroimmune complex (Gonzalez et al., 2014). In microglia, $\mathrm{CB}_{1}$ receptors are expressed at low levels constitutively; however, $\mathrm{CB}_{2}$ receptors become upregulated when microglia become activated (Cabral et al., 2008). Endocannabinoids 2-AG and AEA have been shown to drive microglia toward alternative, anti-inflammatory activation state, M2, and away from classic, pro-inflammatory polarization, M1, which in turn causes microglia to upregulate its own 2-AG synthesizing enzymes (Mecha et al., 2015). Because microglial 2-AG has been shown to promote OPC differentiation (Miron et al., 2013), blocking its degradation could be of use in counteracting demyelination. This has been explored in a mouse model of EAE (Wen et al., 2015), by inhibiting the 2-AG hydrolyzing microglial enzyme ABHD6 (Li et al., 2007; Marrs et al., 2010; Murataeva et al., 2014) with WWL70 (10 mg/kg, IP daily starting at the onset of clinical symptoms on day11 postinoculation). WWL70 increased cerebral 2-AG at day21 , and ameliorated the loss of staining of spinal cord myelin and mature oligodendrocytes in wildtype mice on day-28 (Wen et al., 2015). These results were not seen in $\mathrm{CB}_{2}-\mathrm{KO}$ mice, nor when WWL70 was co-administered with $\mathrm{CB}_{2}$ antagonist AM630 (3 mg/kg), suggesting that microglial 2-AG accumulation is dependent upon $\mathrm{CB}_{2}$ receptor signaling. Co-administration with $\mathrm{CB}_{1}$ antagonist $\mathrm{AM} 281$ failed to interfere with WWL70's effects.

OPC gliogenesis in Borna Disease Virus (BDV) encephalomyelitis, generated in PD28 male Lewis rats (Solbrig et al., 2010), demonstrated that WIN55212-2 (1 mg/kg, IP daily for 7-days starting 1 week after virus inoculation) increased OPC proliferation in striatum, decreased apoptosis of proliferating cells, skewed precursor differentiation away from astrocytes and toward oligodendrocytes, and promoted OPC maturation. In uninfected controls, WIN55212-2 increased proliferation in both PFC and striatum.

In Theiler's murine encephalomyelitis virus-induced demyelinating disease (TMEV-IDD), PD28 female CJL/J mice received an intracerebral injection of the Daniel strain virus (Feliu et al., 2017). When started after symptom onset at day-75, a 10-day treatment with MAGL inhibitor UCM03025 (5 $\mathrm{mg} / \mathrm{kg}$, IP) increased the spinal cord populations of both mature oligodendrocytes and OPCs, and restored MBP level to that of sham controls (Feliu et al., 2017).

In the cuprizone oligodendrotoxic model (Bernal-Chico et al., 2015), PD56 C57BL/6 mice were fed a cuprizone-supplemented diet $(0.3 \%)$ for 3 weeks. Concurrent MAGL inhibitor JZL184 ( $8 \mathrm{mg} / \mathrm{kg}$, IP daily) ameliorated cuprizone-induced reduction in corpus callosum MBP staining (Bernal-Chico et al., 2015), implicating 2-AG-mediated protection.

Seizures are known to accompany demyelination in experimental models (DePaula-Silva et al., 2017; Lapato et al., 2017; Spatola and Dalmau, 2017) as well as MS (Koch et al., 2008; Anderson and Rodriguez, 2011; Sponsler and Kendrick-Adey, 2011). The ECS promotion of OPCs (Solbrig et al., 2010; Feliu et al., 2017) and mature oligodendrocytes (Ribeiro et al., 2013; Wen et al., 2015; Feliu et al., 2017) may counteract demyelination observed in patients with intractable epilepsy (Hu et al., 2016).

\section{CBD and OPCs in Inflammation}

CBD has been promoted for potential therapeutic applications (Devinsky et al., 2014; Blessing et al., 2015; Ibeas Bih et al., 2015) 
including anti-inflammation (Burstein, 2015). Inflammation underlies a range of pathologies including neurodegeneration (Glass et al., 2010; Cunningham, 2013), stroke (Turner and Vink, 2007; Ahmad et al., 2014), and demyelination (Popescu and Lucchinetti, 2012; Kutzelnigg and Lassmann, 2014). To examine CBD's anti-inflammatory impact on OPC survival, cultured OPCs isolated from the forebrain of newborn Wistar rats were exposed to inflammation-related stressors (Mecha et al., 2012). Treatment with CBD (1 $\mu \mathrm{M})$ reduced: (1) caspase-3mediated apoptosis resulting from lipopolysaccharides (LPS) and interferon- $\gamma$ (IFN $\gamma$ )-mediated inflammation (48 h); (2) cell death induced by endoplasmic reticulum stress instigated by tunicamycin $(1 \mu \mathrm{g} / \mathrm{ml}, 24 \mathrm{~h})$; and (3) cell detachment and ROS production in response to hydrogen peroxide $(2 \mathrm{~h})$. CBD was unable to increase OPC proliferation in culture (Mecha et al., 2012), in contrast to its chronic administration in SVZ of adult Swiss mice (Schiavon et al., 2016). CBD did not promote apoptosis in culture, as observed in unstressed cultured oligodendrocytes (Mato et al., 2010). CBD's cellular mechanism(s) have yet to be established for OPC and oligodendrocyte function, but might counter the endocannabinoid responses at their receptors. Further, CBD may target other cell types in the neuro-immune complex, explaining differences between in vitro vs. in vivo models.

\section{PERSPECTIVES}

Although much has been learned about the impact of cannabinoid agonists on oligodendrocytes in health and disease, many questions remain unexplored, such as the cannabinoid impact on OPC local migration (Kirby et al., 2006; Hughes et al., 2013) and glutamate signaling (Spitzer et al., 2016), the oligodendrocyte's ability to produce myelin and provide metabolic support to axons (Zecca et al., 2004; Saab et al., 2013; Simons and Nave, 2015). Cannabinoid agonists also comprise structurally and functional distinct ligands (Howlett

\section{REFERENCES}

Ahmad, M., Dar, N. J., Bhat, Z. S., Hussain, A., Shah, A., Liu, H., et al. (2014). Inflammation in ischemic stroke: mechanisms, consequences and possible drug targets. CNS Neurol. Disord. Drug Targets 13, 1378-1396. doi: 10.2174/ 1871527313666141023094720

Alizadeh, A., and Abdolrezaee-Karimi, S. (2016). Microenvironmental regulation of oligodendrocyte replacement and remyelination in spinal cord injury. J. Physiol. 594, 3539-3552. doi: 10.1113/JP270895

Anderson, G., and Rodriguez, M. (2011). Multiple sclerosis, seizures, and antiepileptics: role of IL-18, IDO, and melatonin. Eur. J. Neurol. 18, 680-685. doi: 10.1111/j.1468-1331.2010.03257.x

Arévalo-Martín, Á., García-Ovejero, D., Rubio-Araiz, A., Gómez, O., MolinaHolgado, F., and Molina-Holgado, E. (2007). Cannabinoids modulate Olig2 and polysialylated neural cell adhesion molecule expression in the subventricular zone of post-natal rats through cannabinoid receptor 1 and cannabinoid receptor 2. Eur. J. Neurosci. 26, 1548-1559. doi: 10.1111/j.1460-9568.2007. 05782.x

Arevalo-Martin, A., Molina-Holgado, E., and Garcia-Ovejero, D. (2016). Cannabinoids to treat spinal cord injury. Prog. Neuropsychopharmacol. Biol. Psychiatry 64, 190-199. doi: 10.1016/j.pnpbp.2015.03.008 et al., 2002; Pertwee et al., 2010; Laprairie et al., 2017; Priestley et al., 2017), and as such, it is important to characterize their pharmacological profiles in cell pathologies related to oligodendrocytes and other cell types in the neuro-immune complex. Although the impact of cannabinoid extracts on MS disease progression remains inconclusive (Pertwee, 2007; Pryce et al., 2015), the outlook is optimistic (Arévalo-Martin et al., 2008; Chiurchiu et al., 2015, 2018). Evidence of cannabinoid agonist effects on oligodendrocyte survival and OPC lifecycle suggests their usefulness in CNS pathologies such as demyelination (Popescu and Lucchinetti, 2012; Kutzelnigg and Lassmann, 2014), neurodegeneration (Ettle et al., 2016; Tauheed et al., 2016), ischemia (Dewar et al., 2003; Mifsud et al., 2014), epilepsy (Friedman and Devinsky, 2015; Stockings et al., 2018), and traumatic injuries to spinal cord (Alizadeh and AbdolrezaeeKarimi, 2016; Levine, 2016; Arevalo-Martin et al., 2016) and brain (Armstrong et al., 2016; Takase et al., 2018).

\section{AUTHOR CONTRIBUTIONS}

AI conceived the idea and approach to the review, wrote and edited the manuscript. CM and EP provided the feedback and edited the manuscript. AH developed approach to the review, structured, wrote and edited the manuscript.

\section{FUNDING}

This work was supported by NIDA grants R01-DA0042157 and P50-DA006634.

\section{ACKNOWLEDGMENTS}

We thank Sandra Kabler and Zachary Zabarsky for thoughtful feedback on the manuscript.

Arévalo-Martin, A., Garcia-Ovejero, D., Gómez, O., Rubio-Araiz, A., NavarroGalve, B., Guaza, C., et al. (2008). $\mathrm{CB}_{2}$ cannabinoid receptors as an emerging target for demyelinating diseases: from neuroimmune interactions to cell replacement strategies. Br. J. Pharmacol. 153, 216-225. doi: 10.1038/sj.bjp. 0707466

Arevalo-Martin, A., Garcia-Ovejero, D., and Molina-Holgado, E. (2010). The endocannabinoid 2-arachidonoylglycerol reduces lesion expansion and white matter damage after spinal cord injury. Neurobiol. Dis. 38, 304-312. doi: 10. 1016/j.nbd.2010.02.002

Arevalo-Martin, A., Garcia-Ovejero, D., Sierra-Palomares, Y., Paniagua-Torija, B., Gonzalez-Gil, I., Ortega-Gutierrez, S., et al. (2012). Early endogenous activation of $\mathrm{CB} 1$ and $\mathrm{CB} 2$ receptors after spinal cord injury is a protective response involved in spontaneous recovery. PLoS One 7:e49057. doi: 10.1371/journal. pone.0049057

Armstrong, R. C., Mierzwa, A. J., Marion, C. M., and Sullivan, G. M. (2016). White matter involvement after TBI: clues to axon and myelin repair capacity. Exp. Neurol. 275, 3328-3333. doi: 10.1016/j.expneurol.2015.02.011

Back, S. A., Gan, X., Li, Y., Rosenberg, P. A., and Volpe, J. J. (1998). Maturationdependent vulnerability of oligodendrocytes to oxidative stress-induced death caused by glutathione depletion. J. Neurosci. 18, 6241-6253. doi: 10.1523/ JNEUROSCI.18-16-06241.1998 
Baumann, N., and Pham-Dinh, D. (2001). Biology of oligodendrocyte and myelin in the mammalian central nervous system. Physiol. Rev. 81, 871-927. doi: 10.1152/physrev.2001.81.2.871

Bernal-Chico, A., Canedo, M., Manterola, A., Victoria Sanchez-Gómez, M., PérezSamartin, A., Rodriguez-Puertas, R., et al. (2015). Blockade of monoacylglycerol lipase inhibits oligodendrocyte excitotoxicity and prevents demyelination in vivo. Glia 63, 163-176. doi: 10.1002/glia.22742

Berrendero, F., Sepe, N., Ramos, J. A., Di Marzo, V., and Fernández-Ruiz, J. J. (1999). Analysis of cannabinoid receptor binding and mRNA expression and endogenous cannabinoid contents in the developing rat brain during late gestation and early postnatal period. Synapse 33, 181-191. doi: 10.1002/(SICI) 1098-2396(19990901)33:3<181::AID-SYN3>3.0.CO;2-R

Bjelke, B., and Seiger, A. (1989). Morphological distribution of MBP-like immunoreactivity in the brain during development. Int. J. Dev. Neurosci. 7, 145-164. doi: 10.1016/0736-5748(89)90065-8

Blessing, E. M., Steenkamp, M. M., Manzanares, J., and Marmar, C. R. (2015). Cannabidiol as a potential treatment for anxiety disorders. Neurotherapeutics 12, 825-836. doi: 10.1007/s13311-015-0387-1

Bortolato, M., Bini, V., Frau, R., Devoto, P., Pardu, A., Fan, Y., et al. (2014). Juvenile cannabinoid treatment induces frontostriatal gliogenesis in Lewis rats. Eur. Neuropsychopharmacol. 24, 974-985. doi: 10.1016/j.euroneuro.2013.12.011

Burstein, S. (2015). Cannabidiol (CBD) and its analogs: a review of their effects on inflammation. Bioorg. Med. Chem. 23, 1377-1385. doi: 10.1016/j.bmc.2015. 01.059

Cabral, G. A., Raborn, E. S., Griffin, L., Dennis, J., and Marciano-Cabral, F. (2008). $\mathrm{CB}_{2}$ receptors in the brain: role in central immune function. Br. J. Pharmacol. 153, 240-251. doi: 10.1038/sj.bjp.0707584

Carrillo-Salinas, F. J., Navarrete, C., Mecha, M., Feliú, A., Collado, J. A., Cantarero, I., et al. (2014). A cannabigerol derivative suppresses immune responses and protects mice from experimental autoimmune encephalomyelitis. PLoS One 9:e94733. doi: 10.1371/journal.pone.009 4733

Chiurchiu, V., Leuti, A., and Maccarrone, M. (2015). Cannabinoid signaling and neuroinflammatory diseases: a melting pot for the regulation of brain immune responses. J. Neuroimmune. Pharmacol. 10, 268-280. doi: 10.1007/s11481-0159584-2

Chiurchiu, V., van der Stelt, M., Centonze, D., and Maccarrone, M. (2018). The endocannabinoid system and its therapeutic exploitation in multiple sclerosis: clues for other neuroinflammatory diseases. Prog. Neurobiol. 160, 82-100. doi: 10.1016/j.pneurobio.2017.10.007

Consroe, P., Musty, R., Rein, J., Tillery, W., and Pertwee, R. (1997). The perceived effects of smoked cannabis on patients with multiple sclerosis. Eur. Neurol. 38, 44-48. doi: 10.1159/000112901

Croxford, J. L., and Yamamura, T. (2005). Cannabinoids and the immune system: potential for the treatment of inflammatory diseases? J. Neuroimmunol. 166, 3-18. doi: 10.1016/j.jneuroim.2005.04.023

Cunningham, C. (2013). Microglia and neurodegeneration: the role of systemic inflammation. Glia 61, 71-90. doi: 10.1002/glia.22350

Dawson, M. R., Polito, A., Levine, J. M., and Reynolds, R. (2003). NG2-expressing glial progenitor cells: an abundant and widespread population of cycling cells in the adult rat CNS. Mol. Cell. Neurosci. 24, 476-488. doi: 10.1016/S10447431(03)00210-0

DePaula-Silva, A. B., Hanak, T. J., Libbey, J. E., and Fujinami, R. S. (2017). Theiler's murine encephalomyelitis virus infection of SJL/J and C57BL/6J mice: Models for multiple sclerosis and epilepsy. J. Neuroimmunol. 308, 30-42. doi: 10.1016/ j.jneuroim.2017.02.012

Devinsky, O., Cilio, M. R., Cross, H., Fernandez-Ruiz, J., French, J., Hill, C., et al. (2014). Cannabidiol: pharmacology and potential therapeutic role in epilepsy and other neuropsychiatric disorders. Epilepsia 55, 791-802. doi: 10.1111/epi. 12631

Dewar, D., and Dawson, D. (1995). Tau protein is altered by focal cerebral ischaemia in the rat: an immunohistochemical and immunoblotting study. Brain Res. 684, 70-78. doi: 10.1016/0006-8993(95)00417-O

Dewar, D., Underhill, S. M., and Goldberg, M. P. (2003). Oligodendrocytes and ischemic brain injury. J. Cereb. Blood Flow Metab. 23, 263-274. doi: 10.1097/01. WCB.0000053472.41007.F9

Dimou, L., and Gallo, V. (2015). NG2-glia and their functions in the central nervous system. Glia 63, 1429-1451. doi: 10.1002/glia.22859
Doetsch, F., Caillé, I., Lim, D. A., García-Verdugo, J. M., and Alvarez-Buylla, A. (1999). Subventricular zone astrocytes are neural stem cells in the adult mammalian brain. Cell 9, 703-716. doi: 10.1016/S0092-8674(00)80783-7

Dubois, J., Dehaene-Lambertz, G., Kulikova, S., Poupon, C., Hüppi, P. S., and Hertz-Pannier, L. (2014). The early development of brain white matter: a review of imaging studies in fetuses, newborns and infants. Neuroscience 276, 48-71. doi: 10.1016/j.neuroscience.2013.12.044

Ebner, S., Dunbar, M., and McKinnon, R. D. (2000). Distinct roles for PI3K in proliferation and survival of oligodendrocyte progenitor cells. J. Neurosci. Res. 62, 336-345. doi: 10.1002/1097-4547(20001101)62:3<336::AID-JNR3>3.0. $\mathrm{CO} ; 2-\mathrm{H}$

Ettle, B., Schlachetzki, J. C. M., and Winkler, J. (2016). Oligodendroglia and myelin in neurodegenerative diseases: more than just bystanders? Mol. Neurobiol. 53, 3046-3062. doi: 10.1007/s12035-015-9205-3

Feliú, A., Bonilla Del Río, I., Carrillo-Salinas, F. J., Hernandez-Torres, G., Mestre, L., Puente, N., et al. (2017). 2-Arachidonoylglycerol reduces proteoglycans and enhances remyelination in a progressive model of demyelination. J. Neurosci. 37, 8385-8398. doi: 10.1523/JNEUROSCI.2900-16. 2017

Fernández-López, D., Pradillo, J. M., García-Yébenes, I., Martínez-Orgado, J. A., Moro, M. A., and Lizasoain, I. (2010). The cannabinoid WIN55212-2 promotes neural repair after neonatal hypoxia-ischemia. Stroke 41, 2956-2964. doi: 10. 1161/STROKEAHA.110.599357

Figlia, G., Gerber, D., and Suter, U. (2018). Myelination and mTOR. Glia 66, 693-707. doi: 10.1002/glia.23273

Friedman, D., and Devinsky, O. (2015). Cannabinoids in the treatment of epilepsy. N. Engl. J. Med. 373, 1048-1058. doi: 10.1056/NEJMra1407304

Garcia-Ovejero, D., Arevalo-Martin, A., Petrosino, S., Docagne, F., Hagen, C., Bisogno, T., et al. (2009). The endocannabinoid system is modulated in response to spinal cord injury in rats. Neurobiol. Dis. 33, 57-71. doi: 10.1016/j. nbd.2008.09.015

Giacoppo, S., Bramanti, P., and Mazzon, E. (2017). Sativex in the management of multiple sclerosis-related spasticity: an overview of the last decade of clinical evaluation. Mult. Scler. Relat. Disord. 17, 22-31. doi: 10.1016/j.msard.2017. 06.015

Giacoppo, S., Galuppo, M., Pollastro, F., Grassi, G., Bramanti, P., and Mazzon, E. (2015). A new formulation of cannabidiol in cream shows therapeutic effects in a mouse model of experimental autoimmune encephalomyelitis. Daru 23:48. doi: 10.1186/s40199-015-0131-8

Glass, C. K., Saijo, K., Winner, B., Marchetto, M. C., and Gage, F. H. (2010). Mechanisms underlying inflammation in neurodegeneration. Cell 140, 918934. doi: 10.1016/j.cell.2010.02.016

Gomez, O., Arevalo-Martin, A., Garcia-Ovejero, D., Ortega-Gutierrez, S., Cisneros, J. A., Almazan, G., et al. (2010). The constitutive production of the endocannabinoid 2-arachidonoylglycerol participates in oligodendrocyte differentiation. Glia 58, 1913-1927. doi: 10.1002/glia.21061

Gomez, O., Sanchez-Rodriguez, M. A., Ortega-Gutierrez, S., VazquezVilla, H., Guaza, C., Molina-Holgado, F., et al. (2015). A basal tone of 2-Arachidonoylglycerol contributes to early oligodendrocyte progenitor proliferation by activating phosphatidylinositol 3-kinase (PI3K)/AKT and the mammalian target of rapamycin (MTOR) pathways. J. Neuroimmune. Pharmacol. 10, 309-317. doi: 10.1007/s11481-015-9609-x

Gomez, O., Sanchez-Rodriguez, A., Le, M., Sanchez-Caro, C., Molina-Holgado, F., and Molina-Holgado, E. (2011). Cannabinoid receptor agonists modulate oligodendrocyte differentiation by activating PI3K/Akt and the mammalian target of rapamycin (mTOR) pathways. Br. J. Pharmacol. 163, 1520-1532. doi: 10.1111/j.1476-5381.2011.01414.x

Goncalves, M. B., Suetterlin, P., Yip, P., Molina-Holgado, F., Walker, D. J., Oudin, M. J., et al. (2008). A diacylglycerol lipase-CB2 cannabinoid pathway regulates adult subventricular zone neurogenesis in an age-dependent manner. Mol. Cell. Neurosci. 3, 526-536. doi: 10.1016/j.mcn.2008.05.001

Gonsalvez, D., Ferner, A. H., Peckham, H., Murray, S. S., and Xiao, J. (2016). The roles of extracellular related-kinases 1 and 2 signaling in CNS myelination. Neuropharmacology 110, 586-593. doi: 10.1016/j.neuropharm.2015.04.024

Gonzalez, H., Elgueta, D., Montoya, A., and Pacheco, R. (2014). Neuroimmune regulation of microglial activity involved in neuroinflammation and neurodegenerative diseases. J. Neuroimmunol. 274, 1-13. doi: 10.1016/j.jneuroim.2014.07.012 
Gonzalez-Reyes, L. E., Ladas, T. P., Chiang, C. C., and Durand, D. M. (2013). TRPV1 antagonist capsazepine suppresses 4-AP-induced epileptiform activity in vitro and electrographic seizures in vivo. Exp. Neurol. 250, 321-332. doi: 10.1016/j.expneurol.2013.10.010

Hamano, K., Iwasaki, N., Takeya, T., and Takita, H. (1996). A quantitative analysis of rat central nervous system myelination using the immunohistochemical method for MBP. Brain Res. Dev. Brain Res. 93, 18-22. doi: 10.1016/01653806(96)00025-9

Hansen, H. H., Azcoitia, I., Pons, S., Romero, J., Garcia-Segura, L. M., Ramos, J. A., et al. (2002). Blockade of cannabinoid $\mathrm{CB}_{1}$ receptor function protects against in vivo disseminating brain damage following NMDA-induced excitotoxicity. J. Neurochem. 82, 154-158. doi: 10.1046/j.1471-4159.2002.00961.x

Hong, S. J., Dawson, T. M., and Dawson, V. L. (2004). Nuclear and mitochondrial conversations in cell death: PARP-1 and AIF signaling. Trends Pharmacol. Sci. 25, 259-264. doi: 10.1016/j.tips.2004.03.005

Howard, B., Chen, Y., and Zecevic, N. (2006). Cortical progenitor cells in the developing human telencephalon. Glia 53, 57-66. doi: 10.1002/glia. 20259

Howlett, A. C., Barth, F., Bonner, T. I., Cabral, G., Casellas, P., Devane, W. A., et al. (2002). International union of pharmacology. XXVII. Classification of cannabinoid receptors. Pharmacol. Rev. 5, 161-202. doi: 10.1124/pr.54. 2.161

Hu, X., Wang, J. Y., Gu, R., Qu, H., Li, M., Chen, L., et al. (2016). The relationship between the occurrence of intractable epilepsy with glial cells and myelin sheath - an experimental study. Eur. Rev. Med. Pharmacol. Sci. 20, 4516-4524.

Hughes, E. G., Kang, S. H., Fukaya, M., and Bergles, D. E. (2013). Oligodendrocyte progenitors balance growth with self-repulsion to achieve homeostasis in the adult brain. Nat. Neurosci. 16, 668-676. doi: 10.1038/nn.3390

Ibeas Bih C, Chen, T., Nunn, A. V., Bazelot, M., Dallas, M., and Whalley, B. J. (2015). Molecular targets of cannabidiol in neurological disorders. Neurotherapeutics 12, 699-730. doi: 10.1007/s13311-015-0377-3

Irving, E. A., Nicoll, J., Graham, D. I., and Dewar, D. (1996). Increased tau immunoreactivity in oligodendrocytes following human stroke and head injury. Neurosci. Lett. 213, 189-192. doi: 10.1016/0304-3940(96)12856-1

Jin, K., Xie, L., Kim, S. H., Parmentier-Batteur, S., Sun, Y., Mao, X. O., et al. (2004). Defective adult neurogenesis in CB1 cannabinoid receptor knockout mice. Mol. Pharmacol. 66, 204-208. doi: 10.1124/mol.66.2.204

Kahle, M. P., and Bix, G. J. (2013). Neuronal restoration following ischemic stroke: influences, barriers, and therapeutic potential. Neurorehabil. Neural Repair 27, 469-478. doi: 10.1177/1545968312474119

Kim, S. H., Won, S. J., Mao, X. O., Ledent, C., Jin, K., and Greenberg, D. A. (2006). Role for neuronal nitric-oxide synthase in cannabinoid-induced neurogenesis. J. Pharmacol. Exp. Ther. 319, 150-154. doi: 10.1124/jpet.106.107698

Kirby, B. B., Takada, N., Latimer, A. J., Shin, J., Carney, T. J., Kelsh, R. N., et al. (2006). In vivo time-lapse imaging shows dynamic oligodendrocyte progenitor behavior during zebrafish development. Nat. Neurosci. 9, 1506-1511. doi: 10. 1038/nn1803

Koch, M., Uyttenboogaart, M., Polman, S., and De Keyser, J. (2008). Seizures in multiple sclerosis. Epilepsia 49, 948-953. doi: 10.1111/j.1528-1167.2008.01565.x

Kutzelnigg, A., and Lassmann, H. (2014). Pathology of multiple sclerosis and related inflammatory demyelinating diseases. Handb. Clin. Neurol 122, 15-58. doi: 10.1016/B978-0-444-52001-2.00002-9

Lapato, A. S., Szu, J. I., Hasselmann, J. P. C., Khalaj, A. J., Binder, D. K., and TiwariWoodruff, S. K. (2017). Chronic demyelination-induced seizures. Neuroscience 346, 409-422. doi: 10.1016/j.neuroscience.2017.01.035

Laprairie, R. B., Bagher, A. M., and Denovan-Wright, E. M. (2017). Cannabinoid receptor ligand bias: implications in the central nervous system. Curr. Opin. Pharmacol 32, 32-43. doi: 10.1016/j.coph.2016.10.005

Levine, J. (2016). The reactions and role of NG2 glia in spinal cord injury. Brain Res. 1638, 199-208. doi: 10.1016/j.brainres.2015.07.026

Li, W., Blankman, J. L., and Cravatt, B. F. (2007). A functional proteomic strategy to discover inhibitors for uncharacterized hydrolases. J. Am. Chem. Soc. 129, 9594-9595. doi: 10.1021/ja073650c

Marinelli, C., Bertalot, T., Zusso, M., Skaper, S. D., and Giusti, P. (2016). Systematic review of pharmacological properties of the oligodendrocyte lineage. Front. Cell Neurosci. 10:27. doi: 10.3389/fncel.2016.00027

Marrs, W. R., Blankman, J. L., Horne, E. A., Thomazeau, A., Lin, Y. H., Coy, J., et al. (2010). The serine hydrolase ABHD6 controls the accumulation and efficacy of
2-AG at cannabinoid receptors. Nat. Neurosci. 13, 951-957. doi: 10.1038/nn. 2601

Marshall, C. A., Suzuki, S. O., and Goldman, J. E. (2003). Gliogenic and neurogenic progenitors of the subventricular zone: Who are they, where did they come from, and where are they going? Glia 43, 52-61.

Marsicano, G., Goodenough, S., Monory, K., Hermann, H., Eder, M., Cannich, A., et al. (2003). CB1 cannabinoid receptors and on-demand defense against excitotoxicity. Science 302, 84-88. doi: 10.1126/science. 1088208

Martinez-Orgado, J., Fernandez-Lopez, D., Lizasoain, I., and Romero, J. (2007). The seek of neuroprotection: introducing cannabinoids. Recent Pat. CNS Drug Discov. 2, 131-139. doi: 10.2174/157488907780832724

Mato, S., Alberdi, E., Ledent, C., Watanabe, M., and Matute, C. (2009). CB1 cannabinoid receptor-dependent and -independent inhibition of depolarization-induced calcium influx in oligodendrocytes. Glia 57, 295-306. doi: 10.1002/glia.20757

Mato, S., Victoria Sanchez-Gomez, M., and Matute, C. (2010). Cannabidiol induces intracellular calcium elevation and cytotoxicity in oligodendrocytes. Glia 58, 1739-1747. doi: 10.1002/glia.21044

McTigue, D. M., and Tripathi, R. B. (2008). The life, death, and replacement of oligodendrocytes in the adult CNS. J. Neurochem. 107, 1-19. doi: 10.1111/j. 1471-4159.2008.05570.x

Mecha, M., Feliu, A., Carrillo-Salinas, F. J., Rueda-Zubiaurre, A., OrtegaGutiérrez, S., de Sola, R. G., et al. (2015). Endocannabinoids drive the acquisition of an alternative phenotype in microglia. Brain Behav. Immun. 49, 233-245. doi: 10.1016/j.bbi.2015.06.002

Mecha, M., Torrao, A. S., Mestre, L., Carrillo-Salinas, F. J., Mechoulam, R., and Guaza, C. (2012). Cannabidiol protects oligodendrocyte progenitor cells from inflammation-induced apoptosis by attenuating endoplasmic reticulum stress. Cell Death Dis. 3:e331. doi: 10.1038/cddis.2012.71

Menn, B., Garcia-Verdugo, J. M., Yaschine, C., Gonzalez-Perez, O., Rowitch, D., and Alvarez-Buylla, A. (2006). Origin of oligodendrocytes in the subventricular zone of the adult brain. J. Neurosci. 26, 7907-7918. doi: 10.1523/JNEUROSCI. 1299-06.2006

Merkle, F. T., Tramontin, A. D., García-Verdugo, J. M., and Alvarez-Buylla, A. (2004). Radial glia give rise to adult neural stem cells in the subventricular zone. Proc. Natl. Acad. Sci. U.S.A. 101, 17528-17532. doi: 10.1073/pnas.0407893101

Michalski, J. P., and Kothary, R. (2015). Oligodendrocytes in a nutshell. Front. Cell Neurosci. 9:340. doi: 10.3389/fncel.2015.00340

Mifsud, G., Zammit, C., Muscat, R., Di Giovanni, G., and Valentino, M. (2014). Oligodendrocyte pathophysiology and treatment strategies in cerebral ischemia. CNS Neurosci. Ther. 20, 603-612. doi: 10.1111/cns.12263

Miron, V. E., Boyd, A., Zhao, J.-W., Yuen, T. J., Ruckh, J. M. Jennifer, L. et al. (2013). M2 microglia and macrophages drive oligodendrocyte differentiation during CNS remyelination. Nat. Neurosci. 16, 1211-1218. doi: 10.1038/nn.3469

Miron, V. E., Kuhlmann, T., and Antel, J. P. (2011). Cells of the oligodendroglial lineage, myelination, and remyelination. Biochim. Biophys. Acta 1812, 184-193. doi: 10.1016/j.bbadis.2010.09.010

Mitew, S., Hay, C. M., Peckham, H., Xiao, J., Koenning, M., and Emery, B. (2014). Mechanisms regulating the development of oligodendrocytes and central nervous system myelin. Neuroscience 276, 29-47. doi: 10.1016/j.neuroscience. 2013.11.029

Molina-Holgado, E., Vela, J. M., Arévalo-Martín, A., Almazán, G., Molina-Holgado, F., Borrell, J., et al. (2002). Cannabinoids promote oligodendrocyte progenitor survival: involvement of cannabinoid receptors and phosphatidylinositol-3 kinase/Akt signaling. J. Neurosci. 22, 9742-9753. doi: 10.1523/JNEUROSCI.22-22-09742.2002

Moreno-Martet, M., Feliu, A., Espejo-Porras, F., Mecha, M., Carrillo-Salinas, F. J., Fernandez-Ruiz, J., et al. (2015). The disease-modifying effects of a Sativexlike combination of phytocannabinoids in mice with experimental autoimmune encephalomyelitis are preferentially due to $\Delta^{9}$-tetrahydrocannabinol acting through $\mathrm{CB}_{1}$ receptors. Mult. Scler. Relat. Disord. 4, 505-511. doi: 10.1016/j. msard.2015.08.001

Murataeva, N., Straiker, A., and Mackie, K. (2014). Parsing the players: 2arachidonoylglycerol synthesis and degradation in the CNS. Br. J. Pharmacol. 171, 1379-1391. doi: 10.1111/bph.12411

Nishiyama, A., Boshans, L., Goncalves, C. M., Wegrzyn, J., and Patel, K. D. (2016). Lineage, fate, and fate potential of NG2-glia. Brain Res. 1638, 116-128. doi: 10.1016/j.brainres.2015.08.013 
Olah, A., Szekanecz, Z., and Biro, T. (2017). Targeting cannabinoid signaling in the immune system: "high"-ly exciting questions, possibilities, and challenges. Front. Immunol. 8:1487. doi: 10.3389/fimmu.2017.01487

Panikashvili, D., Simeonidou, C., Ben-Shabat, S., Hanuš, L., Breuer, A., Mechoulam, R., et al. (2001). An endogenous cannabinoid (2-AG) is neuroprotective after brain injury. Nature 413, 527-531. doi: 10.1038/35097089

Pertwee, R. G. (2007). Cannabinoids and multiple sclerosis. Mol. Neurobiol. 36, 45-59. doi: 10.1007/s12035-007-0005-2

Pertwee, R. G., Howlett, A. C., Abood, M. E., Alexander, S. P., Di Marzo, V., Elphick, M. R., et al. (2010). International union of basic and clinical pharmacology. LXXIX. Cannabinoid receptors and their ligands: beyond CB(1) and CB(2). Pharmacol. Rev. 62, 588-631. doi: 10.1124/pr.110.003004

Popescu, B. F., and Lucchinetti, C. F. (2012). Pathology of demyelinating diseases. Annu. Rev. Pathol. 7, 185-217. doi: 10.1146/annurev-pathol-011811-132443

Priestley, R., Glass, M., and Kendall, D. (2017). Functional selectivity at cannabinoid receptors. Adv. Pharmacol. 80, 207-221. doi: 10.1016/bs.apha. 2017.03.005

Pryce, G., Riddall, D. R., Selwood, D. L., Giovannoni, G., and Baker, D. (2015). Neuroprotection in experimental autoimmune encephalomyelitis and progressive multiple sclerosis by cannabis-based cannabinoids. J. Neuroimmune. Pharmacol. 10, 281-292. doi: 10.1007/s11481-014-9575-8

Ribeiro, R., Yu, F., Wen, J., Vana, A., and Zhang, Y. (2013). Therapeutic potential of a novel cannabinoid agent CB52 in the mouse model of experimental autoimmune encephalomyelitis. Neuroscience 254, 427-442. doi: 10.1016/j. neuroscience.2013.09.005

Richardson, W. D., Kessaris, N., and Pringle, N. (2006). Oligodendrocyte wars. Nat. Rev. Neurosci. 7, 11-18. doi: 10.1038/nrn1826

Rom, S., and Persidsky, Y. (2013). Cannabinoid receptor 2: potential role in immunomodulation and neuroinflammation. J. Neuroimmune. Pharmacol. 8, 608-620. doi: 10.1007/s11481-013-9445-9

Ross, R. A. (2003). Anandamide and vanilloid TRPV1 receptors. Br. J. Pharmacol. 140, 790-801. doi: 10.1038/sj.bjp.0705467

Roth, A. D., and Nunez, M. T. (2016). Oligodendrocytes: functioning in a delicate balance between high metabolic requirements and oxidative damage. Adv. Exp. Med. Biol. 94, 167-181. doi: 10.1007/978-3-319-40764-7_8

Ruparel, N. B., Patwardhan, A. M., Akopian, A. N., and Hargreaves, K. M. (2011). Desensitization of transient receptor potential ankyrin 1 (TRPA1) by the TRP vanilloid 1-selective cannabinoid arachidonoyl-2 chloroethanolamine. Mol. Pharmacol. 80, 117-123. doi: 10.1124/mol.110.068940

Saab, A. S., Tzvetanova, I. D., and Nave, K. A. (2013). The role of myelin and oligodendrocytes in axonal energy metabolism. Curr. Opin. Neurobiol. 23, 1065-1072. doi: 10.1016/j.conb.2013.09.008

Sampaio-Baptista, C., and Johansen-Berg, H. (2017). White matter plasticity in the adult brain. Neuron 96, 1239-1251. doi: 10.1016/j.neuron.2017. 11.026

Sánchez, A. J., and García-Merino, A. (2012). Neuroprotective agents: cannabinoids. Clin. Immunol. 142, 57-67. doi: 10.1016/j.clim.2011. 02.010

Schiavon, A. P., Bonato, J. M., Milani, H., Guimaraes, F. S., and Weffort de Oliveira, R. M. (2016). Influence of single and repeated cannabidiol administration on emotional behavior and markers of cell proliferation and neurogenesis in non-stressed mice. Prog. Neuropsychopharmacol. Biol. Psychiatry 64, 27-34. doi: 10.1016/j.pnpbp.2015.06.017

Shao, B. Z., Wei, W., Ke, P., Xu, Z. Q., Zhou, J. X., and Liu, C. (2014). Activating cannabinoid receptor 2 alleviates pathogenesis of experimental autoimmune encephalomyelitis via activation of autophagy and inhibiting NLRP3 inflammasome. CNS Neurosci. Ther. 20, 1021-1028. doi: 10.1111/cns. 12349

Shen, M., and Thayer, S. A. (1998). Cannabinoid receptor agonists protect cultured rat hippocampal neurons from excitotoxicity. Mol. Pharmacol. 54, 459-462. doi: $10.1124 / \mathrm{mol} .54 .3 .459$

Shouman, B., Fontaine, R. H., Baud, O., Schwendimann, L., Keller, M., Spedding, M., et al. (2006). Endocannabinoids potently protect the newborn brain against AMPA-kainate receptor-mediated excitotoxic damage. $\mathrm{Br}$. J. Pharmacol. 148, 442-451. doi: 10.1038/sj.bjp.0706755

Simons, M., and Nave, K. A. (2015). Oligodendrocytes: myelination and axonal support. Cold Spring Harb. Perspect. Biol. 8:a020479. doi: 10.1101/cshperspect. a020479
Solbrig, M. V., Fan, Y., Hermanowicz, N., Morgese, M. G., and Giuffrida, A. (2010). A synthetic cannabinoid agonist promotes oligodendrogliogenesis during viral encephalitis in rats. Exp. Neurol. 226, 231-241. doi: 10.1016/j.expneurol.2010. 09.003

Spatola, M., and Dalmau, J. (2017). Seizures and risk of epilepsy in autoimmune and other inflammatory encephalitis. Curr. Opin. Neurol 30, 345-353. doi: 10.1097/WCO.0000000000000449

Spitzer, S., Volbracht, K., Lundgaard, I., and Karadottir, R. T. (2016). Glutamate signalling: a multifaceted modulator of oligodendrocyte lineage cells in health and disease. Neuropharmacology 110, 574-585. doi: 10.1016/j.neuropharm. 2016.06.014

Sponsler, J. L., and Kendrick-Adey, A. C. (2011). Seizures as a manifestation of multiple sclerosis. Epileptic Disord. 13, 401-410. doi: 10.1684/epd.2011. 0468

Stockings, E., Zagic, D., Campbell, G., Weier, M., Hall, W. D., Nielsen, S., et al. (2018). Evidence for cannabis and cannabinoids for epilepsy: a systematic review of controlled and observational evidence. J. Neurol. Neurosurg. Psychiatry 89, 741-753. doi: 10.1136/jnnp-2017317168

Sun, J., Fang, Y., Chen, T., Guo, J., Yan, J., Song, S., et al. (2013a). WIN55, 212-2 promotes differentiation of oligodendrocyte precursor cells and improve remyelination through regulation of the phosphorylation level of the ERK $1 / 2$ via cannabinoid receptor 1 after stroke-induced demyelination. Brain Res. 1491, 225-235. doi: 10.1016/j.brainres.2012. 11.006

Sun, J., Fang, Y. Q., Ren, H., Chen, T., Guo, J. J., Yan, J., et al. (2013b). WIN55,212-2 protects oligodendrocyte precursor cells in stroke penumbra following permanent focal cerebral ischemia in rats. Acta Pharmacol. Sin. 34, 119-128. doi: 10.1038/aps.2012.141

Takase, H., Washida, K., Hayakawa, K., Arai, K., Wang, X., Lo, E. H., et al. (2018). Oligodendrogenesis after traumatic brain injury. Behav. Brain Res. 340, 205-211. doi: 10.1016/j.bbr.2016.10.042

Tauheed, A. M., Ayo, J. O., and Kawu, M. U. (2016). Regulation of oligodendrocyte differentiation: Insights and approaches for the management of neurodegenerative disease. Pathophysiology 23, 203-210. doi: 10.1016/j. pathophys.2016.05.007

Tomas-Roig, J., Wirths, O., Salinas-Riester, G., and HavemannReinecke, U. (2016). The cannabinoid CB1/CB2 agonist WIN55212.2 promotes oligodendrocyte differentiation in vitro and neuroprotection during the cuprizone-induced Central Nervous System demyelination. CNS Neurosci. Ther. 22, 387-395. doi: 10.1111/cns. 12506

Trotter, J., Karram, K., and Nishiyama, A. (2010). NG2 cells: properties, progeny and origin. Brain Res. Rev. 63, 72-82. doi: 10.1016/j.brainresrev.2009. 12.006

Turner, R., and Vink, R. (2007). Inhibition of neurogenic inflammation as a novel treatment for ischemic stroke. Drug News Perspect. 20, 221-226. doi: 10.1358/ dnp.2007.20.4.1103527

van der Stelt, M., and Di Marzo, V. (2005). Cannabinoid receptors and their role in neuroprotection. Neuromolecular Med. 7, 37-50. doi: 10.1385/NMM:7: 1-2:037

Vemuri, G. S., and McMorris, F. A. (1996). Oligodendrocytes and their precursors require phosphatidylinositol 3-kinase signaling for survival. Development 122, 2529-2537.

Vigano, F., and Dimou, L. (2016). The heterogeneous nature of NG2-glia. Brain Res. 1638, 129-137. doi: 10.1016/j.brainres.2015.09.012

Wade, D. T., Collin, C., Stott, C., and Duncombe, P. (2010). Meta-analysis of the efficacy and safety of Sativex (nabiximols), on spasticity in people with multiple sclerosis. Mult. Scler. 16, 707-714. doi: 10.1177/1352458510367462

Wen, J., Ribeiro, R., Tanaka, M., and Zhang, Y. (2015). Activation of CB2 receptor is required for the therapeutic effect of ABHD6 inhibition in experimental autoimmune encephalomyelitis. Neuropharmacology 99, 196-209. doi: 10.1016/ j.neuropharm.2015.07.010

Zecca, L., Youdim, M. B., Riederer, P., Connor, J. R., and Crichton, R. R. (2004). Iron, brain ageing and neurodegenerative disorders. Nat. Rev. Neurosci. 5, 863-873. doi: 10.1038/nrn1537

Zhang, R., Chopp, M., and Zhang, Z. G. (2013). Oligodendrogenesis after cerebral ischemia. Front. Cell Neurosci. 7:201. doi: 10.3389/fncel.2013.00201 
Zhang, R., Zhang, Z., and Chopp, M. (2016). Function of neural stem cells in ischemic brain repair processes. J. Cereb. Blood Flow Metab. 36, 2034-2043. doi: 10.1177/0271678X16674487

Zhang, Y., Aizenman, E., DeFranco, D. B., and Rosenberg, P. A. (2007). Intracellular zinc release, 12-lipoxygenase activation and MAPK dependent neuronal and oligodendroglial death. Mol. Med. 13, 350-355.

Zhang, Y., Wang, H., Li, J., Dong, L., Xu, P., Chen, W., et al. (2006). Intracellular zinc release and ERK phosphorylation are required upstream of 12lipoxygenase activation in peroxynitrite toxicity to mature rat oligodendrocytes. J. Biol. Chem. 281, 9460-9470. doi: 10.1074/jbc.M510650200
Conflict of Interest Statement: The authors declare that the research was conducted in the absence of any commercial or financial relationships that could be construed as a potential conflict of interest.

Copyright (c) 2018 Ilyasov, Milligan, Pharr and Howlett. This is an open-access article distributed under the terms of the Creative Commons Attribution License (CC BY). The use, distribution or reproduction in other forums is permitted, provided the original author(s) and the copyright owner(s) are credited and that the original publication in this journal is cited, in accordance with accepted academic practice. No use, distribution or reproduction is permitted which does not comply with these terms. 